\title{
T-SCORM: An Extension of the SCORM Standard to Support the Project of Educational Contents for t-Learning
}

\author{
Francisco Miguel da Silva ${ }^{1}$, Francisco Milton Mendes Neto ${ }^{1}$, \\ Aquiles Medeiros Filgueira Burlamaqui ${ }^{2}$, Diogo Henrique Duarte Bezerra ${ }^{2}$ \\ ${ }^{1}$ Federal University of Semi Arid (UFERSA), Mossoró, Brazil \\ ${ }^{2}$ Federal University of Rio Grande do Norte (UFRN), Natal, Brazil \\ Email: \{miguel.silva, miltonmendes\}@ufersa.edu.br, \{aquiles, diogo\}@natalnet.br
}

Received October $29^{\text {th }}$, 2011; revised November 27 $7^{\text {th }}$, 2011; accepted December $10^{\text {th }}, 2011$

\begin{abstract}
The Interactive Digital Television (iDTV) has facilitated and expanded the communication and interaction in activities of knowledge acquisitions, entertainment and recreation in Distance Learning field. This new way of teaching and learning has been called t-Learning. In this context, the Learning Objects (LOs) have an important role to assist in the electronic courses' development. Due the fast progress of e-Learning, some efforts to standardization have appeared in order to enable the reusability of educational contents and interoperability among systems, and one of these standards is the Sharable Content Object Reference Model (SCORM). Therefore, the main goal of this work is to present an extension of SCORM aiming to adapt it in order to improve the search and navigation of LOs with educational content for t-Learning. That will be done through an authoring tool named T-SCORM ADAPTER, which will be able to apply this extension in a fast and efficient way.
\end{abstract}

Keywords: iDTV; t-Learning; Learning Objects; SCORM; Extension

\section{Introduction}

Nowadays, the appreciation of knowledge influences the way in which people acquire skills by making a particular person search for alternative and flexible ways of learning. According to (Girardi, 2002), this appreciation of knowledge makes that each individual always is looking for new ways to improve and increase their learning level constantly.

Having the television as Brazil's most popular media, it appears as a solution for disseminating quality and interactive content.

This happens because of the digitization ${ }^{1}$ process, which enables audio and video applications to be executed (Monteiro et al., 2008). The Interactive Digital Television (iDTV) is becoming a reality in the world, due mainly to the advances in telecommunications. The Brazilian government with the development of (SBTVD) ${ }^{2}$, short for Sistema Brasileiro de Televisão Digital (English: Brazilian Digital Television System) has also contributed to this aspect (SBTVD, 2007).

Based on this reality, there is the problem in how to adjust educational contents, so as to better support the search and navigation mechanism to make them available in the iDTV platform in order to present an effective and personalized learning. Another problem that arises in this context is how to make the Learning Objects (LOs) ${ }^{3}$ become more suitable through their

${ }^{1}$ Conversion of an analogue signal or code into a digital signal or code. http://en.wikiversity.org/wiki/Digital_Libraries/Digitization

${ }^{2}$ The SBTVD was established by Presidential decree $(5.820,2006)$, it is composed of a Manager Group, a Development Committee and an Advisory Committee. This decree also establishes guidelines for the transition of analogue transmission for the digital transmission system of sound and image broadcasting services and the television retransmission service. http://www.planalto.gov.br/ccivil_03/_Ato2004-2006/2006/Decreto/D5820. htm

${ }^{3}$ Los examples include multimedia and instructional content, and instructtional software (Lucia, Azevedo, \& Anna, 2007). specification in $\mathrm{SCORM}^{4}$, aiming at the proper presentation for iDTV.

To fill this gap, this paper proposes an extension to the SCORM standard in order to better support in an effective manner the search, navigation and visualization of LOs with educational contents for t-Learning 5 .

This paper is structured as follows. First, we describe the main features of iDTV, Distance Education and t-Learning. Next we present the definitions of LOs as well as the standards for their development and description. Then we expose the details of our proposal and the authoring tool T-SCORM ADAPTER. After that, we present and discuss similar approaches. Finally, we draw some conclusions and motivation for future work.

\section{Interactive Digital and Distance Educational}

It is possible to find in the literature many concepts about Distance Education. In this work, we will use the definition established by the (SEED), short for Secretaria de Educação a Distância (English: Secretariat of Distance Education) of the Ministry of Education and Culture (MEC), in the decree (5.622, 2005). In its article 1st, this decree defines the Distance Education as being:

"[...] educational modality in which the didactic-pedagogical mediation in the teaching-learning process occurs with the use of resources along with information and communication tech-

\footnotetext{
${ }^{4}$ SCORM is a collection of standards and specifications for web-based e-learning. It defines communications between the client side content, and a host system called the run-time environment, which is commonly supported by a learning management system (ADL, 2010).

${ }^{5}$ t-Learning is a shorthand meaning for TV-based interactive learning. http://www.it.lut.fi/eaeeie05/proceedings/p21.pdf
} 
nologies, with students and teachers by developing educational activities in places or different times".

Based on this definition, we can present the iDTV as a means of support for distance learning, and with the SBTVD expansion and the interactivity provided by the Ginga middleware, good opportunities show up to the development of educational applications being an innovator in iDTV and characterizing the modality of teaching-learning named as t-Learning.

The e-Learning and t-Learning have different scopes taking into account that e-Learning is highly suitable for a formal education environment. That is, it is supported by methodologies quite defined to carry out an outline and summary of topics to be covered in an education or training course. t-Learning, in turn, is more appropriate for an informal approach, which allows the learning through the entertainment (Pazos-Arias et al., 2008).

As it is shown in Figure 1, the interactivity features represent a great advantage over the traditional television programs, in view of the fact that it makes the learning experience more enjoyable. The interactivity allows among other things, the user should influence the presentation of contents and assesses his knowledge by on-line tests.

\section{Learning Objects}

A relevant concept in relation to the content of teaching-learning in the field of Distance Education is the Learning Object (LO). According to the Learning Technology Standard Committee (LTSC) of the Institute of Electrical and Electronics Engineers (IEEE), a Learning Object is defined as any entity, digital or non-digital, that may be used for learning, education or training (LTSC, 2002).

According to (Americo, 2010), the LOs are considered information blocks and present the following features: 1) reusability-Reusable several times in different learning environments; 2) adaptability_-Adaptable to any teaching environment; 3) granularity-pieces of content, in order to facilitate its reusability; 4) accessibility - easily accessible on the Internet to be used in many locations; 5) durability-possibility to be used continuously, regardless technology change; 6) interoperability-ability to operate through a hardware variety, operating systems and browsers, i.e. effective exchange between different systems.

The efforts for development of standards aiming to the description of LOs may be exemplified by the work of important organizations such as IEEE and the Global Learning Consortium, which have proposed the Learning Object Metadata (LOM) standard (LOM, 2002). The metadata standard LOM

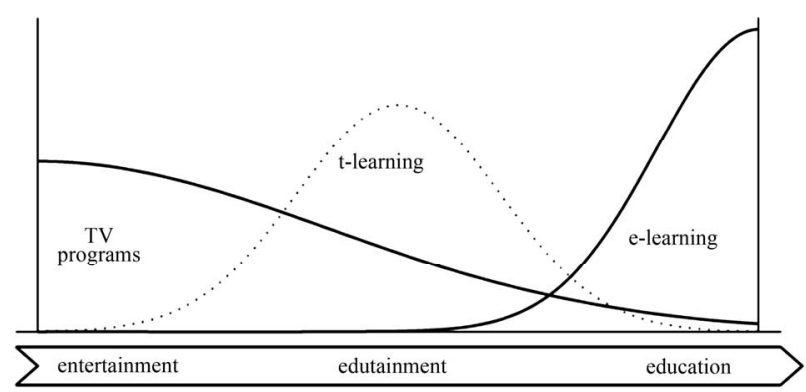

Figure 1.

t-Learning: between pure entertainment and formal education. Source: (Pazos-Arias et al., 2008). allows the LOs be classified, reused and found by searching tools in an appropriate manner. The main elements of LOM are described below:

- General: Gather information in general, which describe the LO as a whole;

- Life Cycle: Gather features concerning to the history and Status Quo of the LO;

- Meta-Metadata: Collect information about the metadata instances;

- Technical: Gather the features and the technical requirements of LO;

- Educational: Collect the pedagogical and educational characteristics of LO;

- Rights: Describe Copyright And Other Restrictions;

- Relation: Define the relation characteristics among the LOs;

- Annotation: Comments regarding to educational use and information of LO;

- Classification: Describe the LO in relation to a classification of a specific system.

The Shareable Content Object Reference Model (SCORM), which has been developed by Advanced Distributed Learning (ADL), is also widely used and describes how the content could be modeled and how the learning management environments should handle such content to make its reuse viable (ADL, 2010).

The standard SCORM content can be distributed to the students by any Learning Management System (LMS), which has to be compatible with SCORM and use the same version of standard (ADL, 2010). Essentially the context description model of SCORM defines a set of metatags and statements to be used in the description files or in the content, aiming for the transfer information to the LMS about the content and the interaction of students with the content.

The Figure 2 shows the SCORM organization as a collection of standards and specifications of other organizations contained or referenced in the model.

To enable the content aggregation in a format that is easily interpretable and transferable among systems on the Internet, the ADL has adopted the definition of a special file named (imsmanifest.xml), encoded in xml, which describes the different components and resources. It has markers for all the features of the SCORM provided in the configuration files, as well as the locations of the referenced files by these components.

The Figure 3 shows a pseudocode example of imsmanifest.xml.

As it is shown in Figure 3, the imsmanifest.xml starts by defining the language and version of the file. Then it presents the main element $<$ manifest $>$ in which are described the domains that support the entire coding.

The imsmanifest.xml structure is composed by the following elements.

$<$ metadata $>$ : Used in any component of the data model and the content package ${ }^{6}$;

$<$ organizations>: Mandatory in case of Content Aggregation Package $^{7}$;

$<$ item $>$ : Corresponds to an activity of content model;

$<$ resources $>$ : Contains a set of references to the different resources;

\footnotetext{
${ }^{6}$ Concerning to SCORM Content Package, see Figure 2.

${ }^{7}$ Concerning to Content Aggregation Model (CAM), defines the method of packing, labeling, research and content exchange.
} 
$<$ files $>$ : Used to reference the location of archive which belongs to the resource;

$<$ manifest $>$ : In the Content Aggregation, the whole manifest is referenced, or just a few parts of its components.

\section{Extension Proposal of SCORM Standard}

The extension of the SCORM standard proposed in this paper has as main goal to improve the support to the search and the navigation making available the LOs for the iDTV platform.

The great advantage of this method is that, it will enable a system to search for information contained in the metadata of the LOs with educational content created specifically for t-Learning within the imsmanifest.xml.
First we start with a scenario in which there is already an LMS working in selecting and distribution of LOs for courses on the iDTV platform regarding to t-Learning context. Then the objective of this work is to improve the selecting process made by the LMS, adding specific t-Learning information in the metadata of these LOs.

Currently, there is no repository for educational content specific for a t-Learning environment in the international or national context. According to (Bez, 2009), the most part of the LMSs has worked with web content. Then, it is not being possible to convert this content for Digital TV yet. This occurs mainly due to the fact of the navigability between these technologies be different.

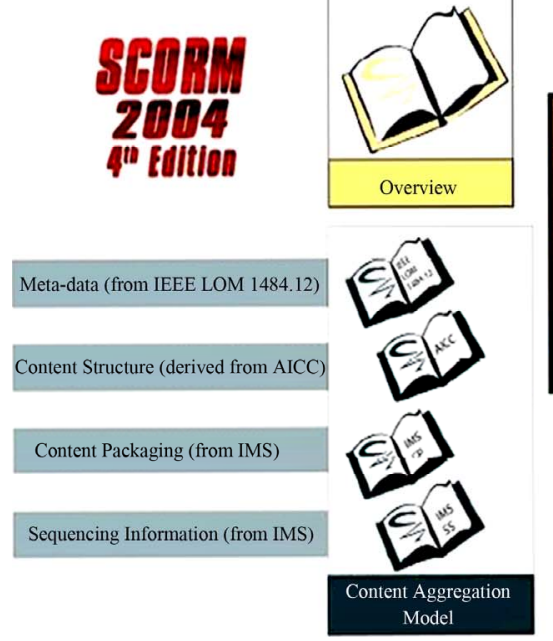

Source: [http://www.scorm 2004.fr]].

Figure 2.

SCORM 2004 specification books.
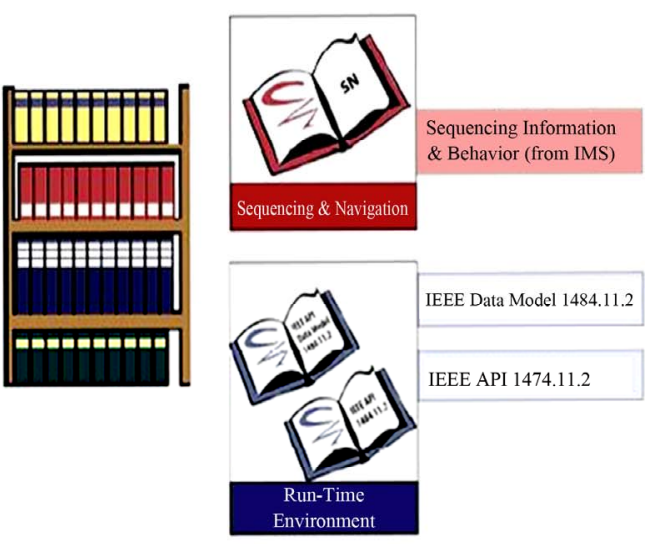

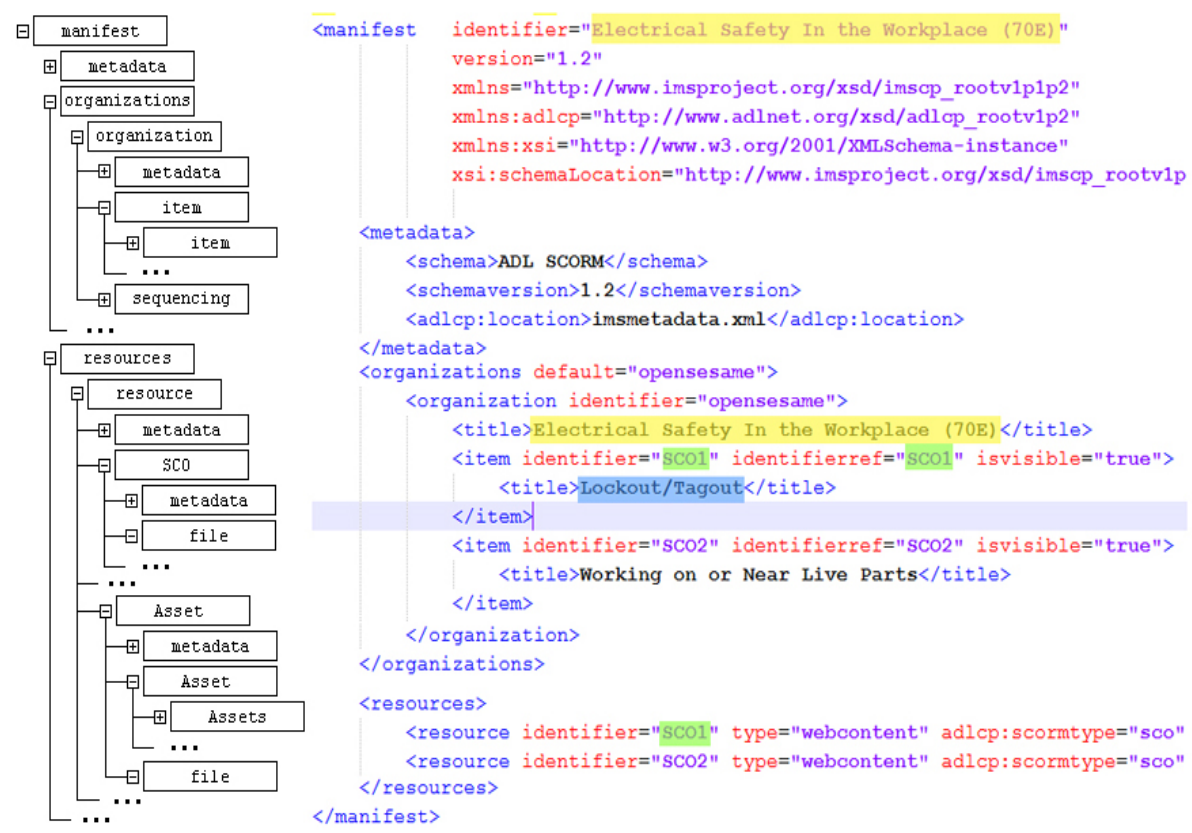

Figure 3.

Structure and pseudocode of imsmanifest.xml. 
The proposed extension contemplates an adaptation of metadata information in the current SCORM standard based on LOM standard. New elements have been proposed in order to give more emphasis to the information of these metadata related to iDTV.

The intention of improving the quality of these metadata, and it is just for, according to the preferences and cognitive characteristics contained in the students' profiles, the LMS can manage in a quickly and efficient manner, to seek and make these LOs available for students in the iDTV platform.

\section{New Metadata Model}

Metadata, in a brief answer, is defined as data about data, which describe them (semantic and syntactically), and in which is possible to structure and manage the information in different environments (Alves et al., 2006).

It is being proposed in this work, new elements of metadata, where they become child nodes in the main structure of the metadata model of LOM, which SCORM is based on.

With the new elements inserted in the LOM structure, we have twelve categories that make it possible to specify in a more accurate way the LOs metadata with educational content for iDTV. With these new elements added, it will be possible to describe specific information of LOs for iDTV, such as: interactivity level, copyright description, precise description on educational content in digital format, etc.

In Figure 4, it is shown an overview of the new structure proposed to the LOM. In blue, we have the original metadata elements in the LOM structure. In green, we have the new categories of elements proposed by the extension. Finally, in orange, we have the LOM's adaptation with the new metadata structure.

In spite of the actual LOM metadata structure within the SCORM already includes metadata information for categories such as educational and rights, these categories, as well as the other ones, classify and specify the LOs metadata in a very generic way and these categories do not have fields to treat in a better quality this exclusive information for iDTV.

With the inclusion of these new elements adapted in the structure, we now have twelve categories that allow us to specify in a more accurate way the metadata of the OAs with educational content for TVDi.

With the inclusion of these new elements, it will be possible to describe specific information of LOs for iDTV, such as the interactivity level in which it could describe the system characteristics, since in iDTV this resource may not be available. We also have the description of digital content rights, where, in the case of special particularities, it will be possible to specify in detail the information on educational content in digital format, among other information.

This adjustment in the categories allows to describe clearer information on the media content with educational and training, in addition to helping any search mechanism to become faster and effective in gathering information directly in the metadata making with these LOS be suitable in a correct way for the specific public.

Figure 5 shows the architecture and how is applied the T-SCORM extension.

As shown in Figure 5, the Vocabulary Creator $^{8}$ is in charge of adding the new elements of T-SCORM extension. The new elements shall contain the information relating to the new metadata parameters and inserted in the LOM structure based on SCORM.

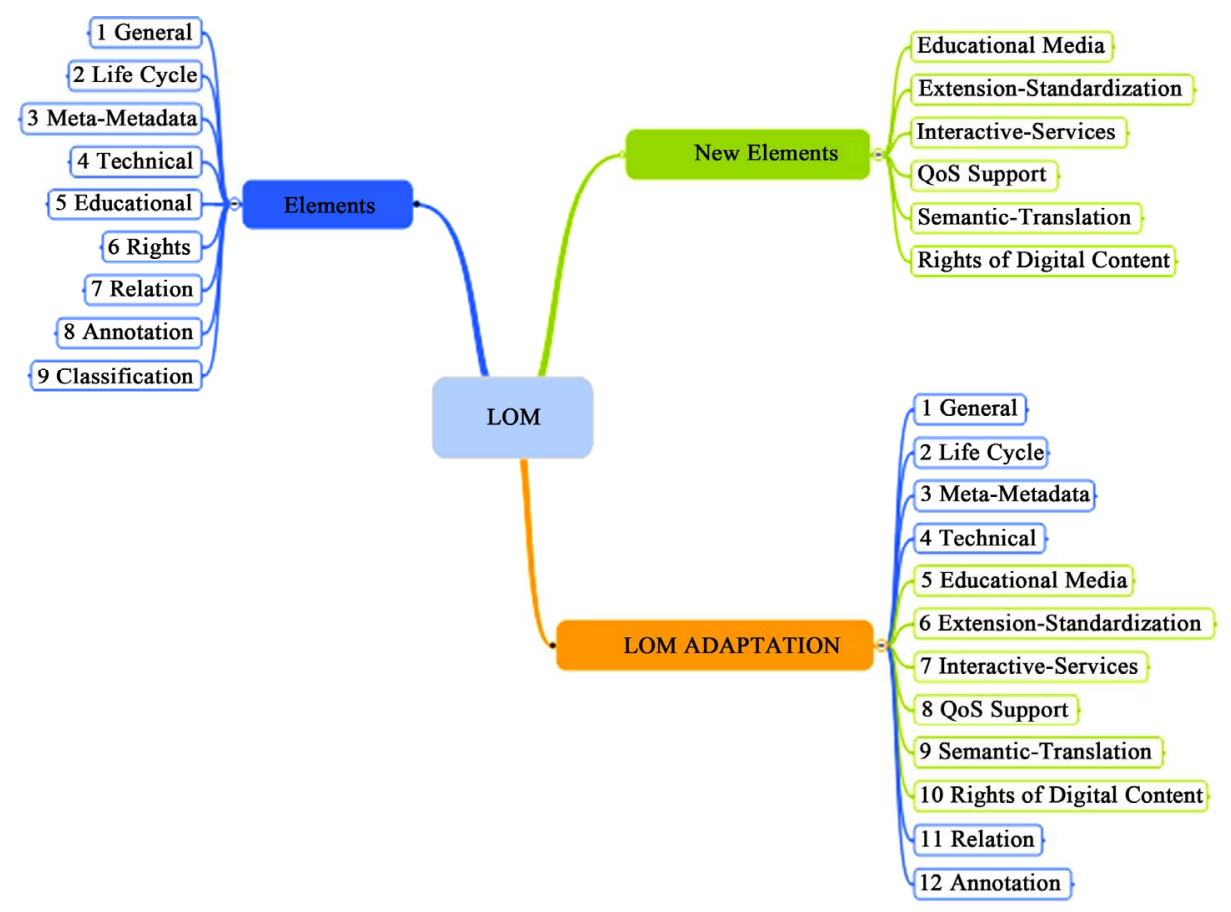

Figure 4.

New structure of LOM for iDTV. 
The LO must be created and edited according to the specifications of SCORM standard. It has been used in this work the freeware tool Reload Editor ${ }^{9}$ for LO creation and editing.

Once edited, the Content Creator ${ }^{10}$ for iDTV will compose the LOs in accordance with SCORM. However, the Content Creator will add the new extension using the T-SCORM ADAPTER tool proposed in this paper. This tool will read the imsmanifest.xml file created in the first place.

This will ensure that the T-SCORM extension may be added with the new metadata elements within the LOM structure, improving the classification and the specification of LOs with educational content for iDTV.

After complete such information, the T-SCORM will save the file with the changes related to the new metadata elements, but keeping the original structure (markers and header) ${ }^{11}$ of imsmanifest.xml, which is demanding for recognition by the LMS as a SCORM content package.

\section{Authoring Tool T-SCORM ADAPTER}

To facilitate the process of reading and adding of the T-SCORM extension, it has been developed the T-SCORM ADAPTER tool, which is able to apply the extension proposed within the imsmanifest.xml structure.

In Figure 6, it can be seen that the tool has a friendly interface and easy to use, with the tabs separated in an adequate manner to input the new information in order to compose the new metadata of LOs for iDTV.

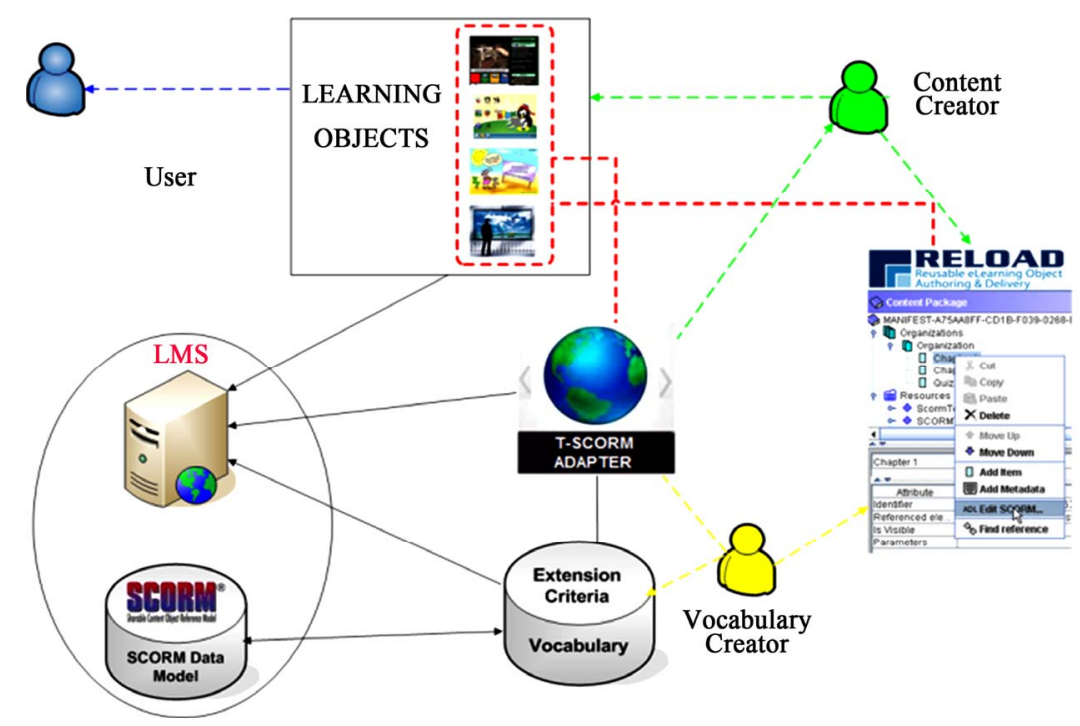

Figure 5.

Architecture of T-SCORM extension.

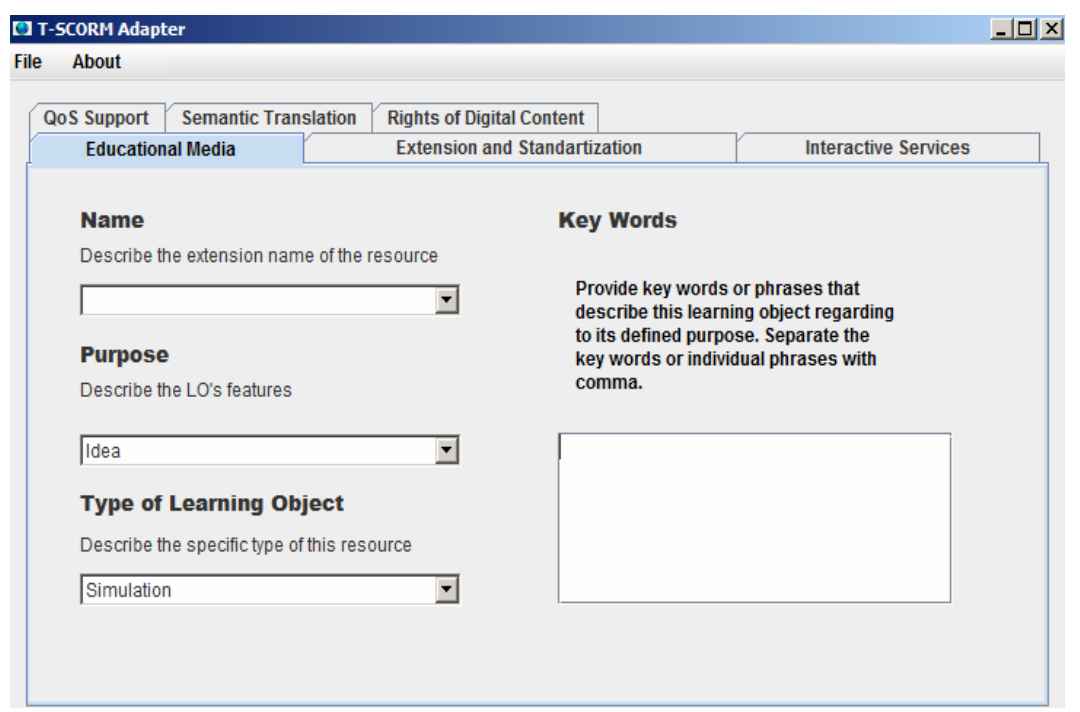

Figure 6.

T-SCORM adapter.

\footnotetext{
9http://www.reload.ac.uk

${ }^{10}$ Subject in charge of create the LOs applying the T-SCORM extension.

${ }^{11}$ See the pseudocode example in Figure 3.
} 
The Figure 7 shows a user scenario of the T-SCORM ADAPTER to modify the imsmanifest.xml applying just one element of the extension.

As shown in Figure 7, in step 1, the user selects the menu File-Import Mani-fest.xml. In step 2, locate the imsmanifest.xml file in the directory. In step 3, put the LO name, in which the metadata will be changed and fill the fields with the information scrolling the menu tabs. In step 4, to save the changes carried out, select the menu File-Save. The information is saved and inserted automatically in the imsmanifest.xml, but keeping its original structure to be received by the LMS.

In Figure 8, it is shown the imsmanifest.xml before and after the addition of metadata in the element <educationalmidia> edited by T-SCORM ADAPTER.

\section{Related Work}

In (Rey-Lopez et al., 2009), it is proposed an adaptation in the Shareable Content Object (SCO) ${ }^{12}$. In the proposed extension, new elements have been introduced in the data model, allowing the objects can request to the LMS information about the user's characteristics and thus, show the content in accordance with such information. At the activity level, new sequencing rules have been created, and making the presented structure to the users depends on their cognitive status and preferences.

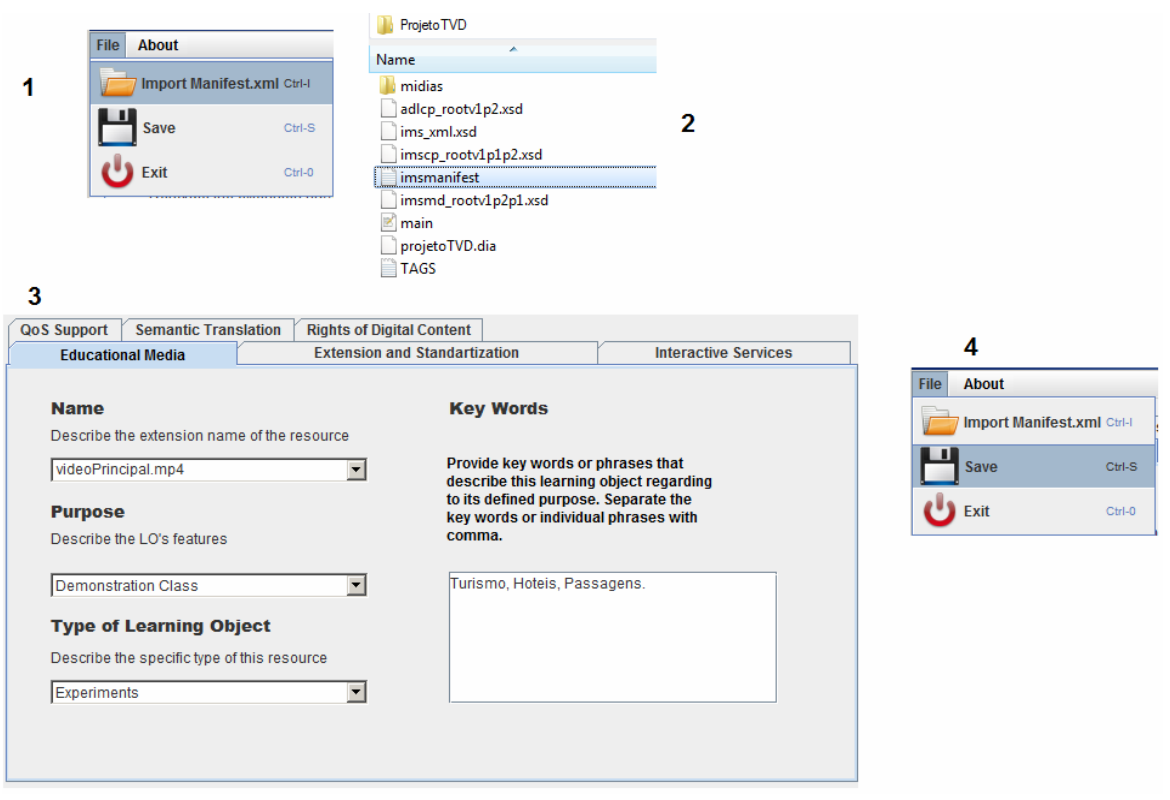

Figure 7.

User scenario of T-SCORM ADAPTER.

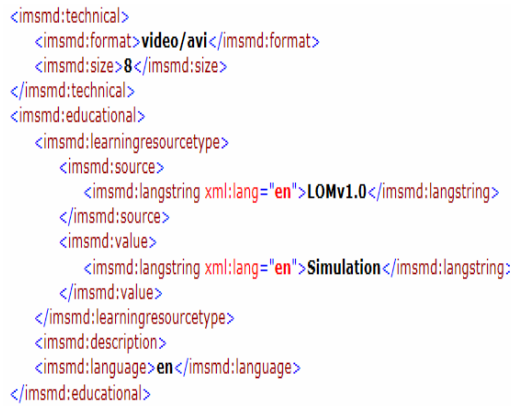

Metadata created by Reload Editor

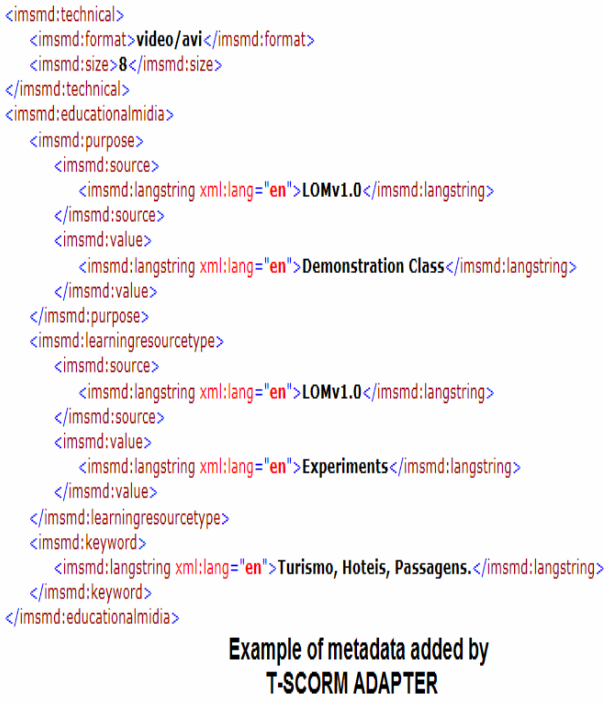

Figure 8.

Editing example of imsmanifest.xml.

${ }^{12}$ Functional component of SCORM. 
The information about these adaptation parameters are obtained starting from a user profile, using inference rules. As a result, courses created are obtained with the purpose of be personalized before make them available to the user. In Figure 9, it is shown the target scenario of this adaptation.

The focus of our work is different, considering the fact that we are proposing an extension of the SCORM standard directly in the metadata of LOM standard, improving the support to educational content through a detailed specification in how the LOs could be better delivered on the iDTV platform.

(Simões, Luis, \& Horta, 2004) introduce a proposal for an extension of the SCORM standard, which allows the modeling of a course related to the entities that surround the LOs and the aggregation content. It is suggested the creation of a new category Environmental in the LOM standard in parallel with the current categories.

In Figure 10, it is shown the recursive hierarchy proposed by the authors. The fields for the data may be related to describe, in an arbitrary manner, complex structures that represent modeled entities.
In Figure 11, it is shown a recursive item in the application and its pseudocode.

The extension presented in (Simões, Luis, \& Horta, 2004) has similarity with the extension proposed in this paper regarding to proposing changes in the structure of the LOM standard. However, our proposal is to create more elements in order to better support the educational content contained in LOs for iDTV.

\section{Conclusion and Future Work}

We have presented in this paper an extension proposal to the SCORM standard (T-SCORM) in order to better support the specification and classification of LOs with educational content for t-Learning. An authoring tool has been proposed (T-SCORM ADAPTER), which is able to read the imsmanifest.xml file and restructure only the metadata of LOs with educational content created to the iDTV platform with no changes in the original structure of the SCORM, which is mandatory to be accepted by a LMS.

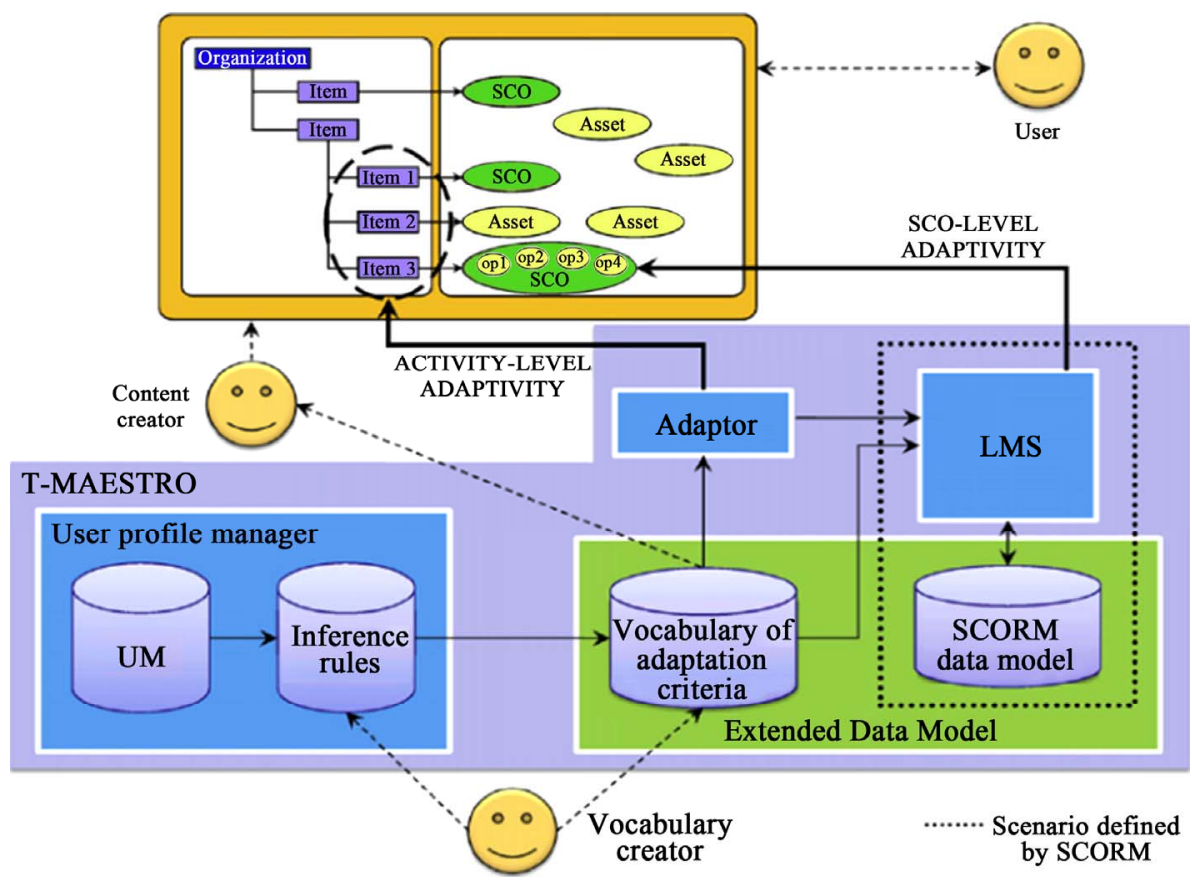

Figure 9.

Target scenario. Source: (Rey-Lopez et al., 2009).

\begin{tabular}{|c|c|l|c|c|}
\hline $\mathrm{Nr}$ & Name & \multicolumn{1}{|c|}{ Description } & Multiplicity & Type \\
\hline 10 & Environmental & $\begin{array}{l}\text { This category models the environment where the } \\
\text { content aggregation is inserted in. It describes the } \\
\text { course entities that are related with the learning } \\
\text { contents. }\end{array}$ & Cor 1 & Container \\
\hline 10.1 & Item & Entity in the content aggregation environment. & 1 or More & Container \\
\hline 10.1 .1 & Type & Entity type. & 1 & Vocabulary \\
\hline 10.1 .2 & Value & Entity content or value. & 0 or 1 & LangString \\
\hline 10.1 .3 & Metadata & Metadata describing this entity. & Container \\
\hline 10.1 .4 & Item & $\begin{array}{l}\text { Sub-entity. The structure of this element is } \\
\text { represented the same as 10.1 ltem }\end{array}$ & 0 or More & Container \\
\hline
\end{tabular}

Figure 10.

Extension category. Source: (Simões, Luis, \& Horta, 2004). 

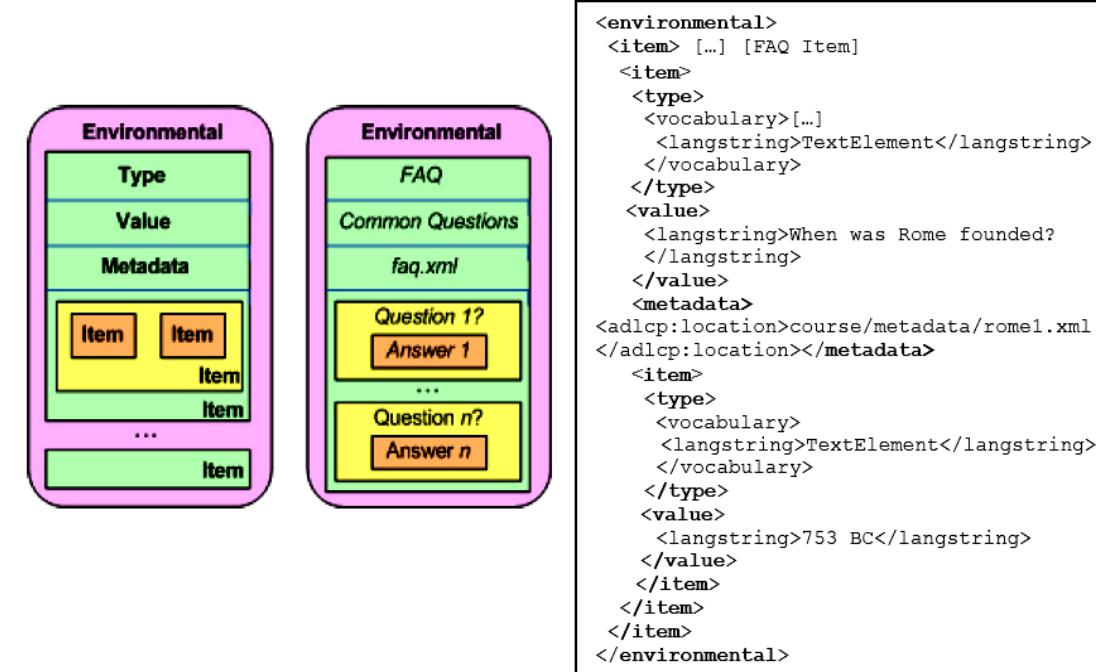

Figure 11

Application with the recursive item and xml code. Source: (Simões, Luis, \& Horta, 2004).

The new elements of the proposed extension have been inserted within the metadata structure of LOM. This way, it was possible to make a detailed and specific classification of information of these metadata. In the context learning, any LO which has in its content educational videos, or training for that matter, it can be described in all its didactic aspects. In addition, there will be containers for technical specification related to iDTV platform.

As future work, we intend to carry out a test in a classroom with educational videos in iDTV applications. A case study will be performed to show the benefits of the proposed approach.

In addition, it will also be analyzed how the communication between the GINGA middleware and the LMS, which will make the search and the availability of such content with the T-SCORM extension already sapplied and being the LOs in accordance with the SCORM standard.

\section{REFERENCES}

ADL. (2010). Advanced distributed learning. URL. http://www.adlnet.org Americo, M. (2010). TV digital: Propostas para o desenvolvimento de conteúdo sem animação para o ensino de ciências. Bauru, SP: Faculdade de Ciências, Universidade Estadual Paulista.

Alves, L. G. P., Kulesza, R., Silva, F. S., Jucá, P., \& Bressan, G. (2006). Análise comparativa de metadados em TV digital. In Simpósio brasileiro de redes de computadores (Vol. 50, pp. 87-98). Curitiba, PR: SBC.

Bez, M., Silva, J. M. C., Santos, E., Primo, T., \& Bordignon, A. (2009). OBAA project: An approach to interoperable learning objects based on web and digital television. Proceedings of the 9th WCCE, Bento Gonalves, 27-31 July 2009.
Girardi, R. A. D. (2002). Framework para coordenação e mediação e web services modelados como learning objects para ambientes de aprendizado na web. Rio de Janeiro, RJ: Pontifícia Universidade Católica do Rio de Janeiro.

LOM. (2002). Learning object metadata. URL. http://tsc.ieee.org/wg12/20020612-Final-LOM-Draft.html

LTSC (Learning Technology Standards Committee). (2002). Draft standard for learning object metadata. IEEE standard 1484.12.1. URL. http://ltsc.ieee.org/wg12/files/LOM_1484_12_1_v1_Final_Draft.pdf

Lúcia, C. P., Azevedo, N., \& Anna, C. A. (2007). Objetos de aprendizagem: Uma proposta de recurso pedagógico/organização. Brasília: MEC, SEED, 154

Monteiro, B. S., Prota, T. M., Souza, F. F., \& Gomes, A. S. (2008). Desenvolvimento de objetos de aprendizagem para TVDi. In Simpósio brasileiro de informática na educação (pp. 1-10). Fortaleza, CE: SBC.

Pazos-Arias, J. J., López-Nores, M., García-Duque, J., Díaz-Redondo, R. P., Blanco-Fernández, Y., Ramos-Cabrer, M., Gil-Solla, A., \& Fernández-Vilas, A. (2008). Provision of distance learning services over Interactive Digital TV with MHP. Journal of Computers \& Education, 50, 927-949.

Rey-Lopez, M., Diaz-Redondo, R. P., Fernandez-Vilas, A., Pazos-Arias, J. J., Garcia-Duque, J., Gil-Solla, A., \& Ramos-Cabrer, M. (2009). An extension to the ADL SCORM standard to support adaptivity: The t-learning case-study. Computer Standards Interfaces, 31, 309318. doi:10.1016/j.csi.2008.02.006

SBTVD. (2007). Sistema brasileiro de TV digital. URL. http://sbtvd.cpqd.com.br/

Simões, D., Luis, R., \& Horta, N. (2004). Enhancing the SCORM modelling scope. Proceedings of IEEE International Conference on Advanced Learning Technologies, Joensuu, 30 August-1 September 2004, 238-239. 